\title{
Association of coronary risk factors and behaviours in old age
}

Keywords: Coronary Risk Factors; Behaviour

\section{Introduction}

It is known that atherosclerosis is a slow, progressive disease that starts in childhood and usually manifests itself clinically much later, as it has been demonstrated by several authors [1-7], including genetic predisposition, the environment, harmful behaviours and coronary risk factors (RFs) that produce a disease initially asymptomatic. Intimal thickening of the coronary arteries has been found during autopsies performed on infants who died from different causes to less than 1 year of age.

Cardiovascular RFs and behaviours interact during adulthood with the sad privilege of being the first cause of disability and death. Identify and treat RFs in childhood and adolescence would be the most important value of Cardiovascular Prevention with the intention of achieve at a high age with the lowest symptoms and with the greatest possible autonomy.

During the last century, life expectancy increased rapidly in Europe as well as in other parts of the world. Life expectancy is a health indicator of a given population, while the term longevity simply means an average life expectancy.

Long-lived patients who are still autonomous may hypothetically have protective factors and/or fewer RFs which afford a better quality of life.

In Okinawa, Japan, the proportion of centenarians is the highest in the world (33.6/100000 inhabitants). People in Japan consume a diet based on vegetables and fish, continue being physically active until old age, and women reach their menopause at a later age.
In the Okinawan centenaries, a greater activity of the gene that regulates the production of the HLA protein was detected, which reduces the risk of the autoimmune diseases.

Comparative studies between Japan and some western countries clearly reveal the difference in longevity of its inhabitants.

The decline in mortality in the Japanese people is not very clear, but it is undoubtedly influenced in the general improvement of health consideration of a number of factors such as diet, work, social relations, primary health care, public health services, the economy, among others. Socioeconomic factors were also responsible for improving health. The period 1965/86, during which life expectancy grew dramatically, coincided with a marked decline in inflation and the unemployment rate [8].

\section{Age and Gender}

Age is a prognostic factor of great importance, already recognized by Benjamìn Gompertz (insurance actuary) in 1825, and is the most powerful independent RF for the prognosis of death and atherosclerosis disease. He has shown how the curve of human survival would be getting closer to the curve of ideal survival, and has made the scientific demonstration that as the age grows, it diminishes the human capacity to prevent its physical decay.

Age is the most powerful risk factor for hypertension, death, and cardiovascular death [9]. Male sex is associated with greater cardiovascular complications.
Carlos Alberto Paterno Marchioli

Council of Epidemiology and Cardiovascular Prevention, Italy

Author for correspondence:

carlos_paterno@tiscali.it

Submitted: 09 May 2017

Accepted: 03 July 2017

Published online: 10 July 2017 
The role of RFs on cardiovascular morbidity and mortality may be influenced by age [10], gender [11], and by ethnic or geografic factors [12].

\section{High Blood Pressure}

The association between high blood pressure (HBP) and cardiovascular disease and mortality has been the subject of numerous observational studies. Arterial hypertension afflicts up to $20-40 \%$ of the adult population in Western industrialized nations [13]. From a long time ago it has been demonstrated that hypertension is also a major RF in the elderly [14-16].

And a number of randomized controlled trials have shown that antihypertensive drug treatment is clearly beneficial even in the very elderly up to 80 years of age [17-21]. Patients with a history of hypertension have at least six times greater risk of heart failure than do individuals without that a history [22].

No specific guidelines exist for hypertension management for this particular elderly population. Data from clinical trials including HYVET favour thiazide diuretics, angiotensin converting enzyme inhibitors and calcium channel blockers for either monotherapy or combination therapy for hypertension in the elderly [23].

\section{Cholesterol}

Numerous observational studies have confirmed the predictive role and existence of a causal relationship between cholesterolemia and coronary heart disease.

Cholesterol is chemically an alcohol, organic substance heritage of the animal Kingdom, even if in the cardiovascular system it acts as a fat, constituting the most important RF, level-dependent, of human atherosclerosis (Framingham Heart study, MRFIT study).

The chemical structure of cholesterol is more complex than other lipids: it can be alternatively present as "free" alcohol, or in "ester" form.

It is present in all the animal tissues and it is abundant in the nervous tissue. Degenerative changes of the cerebral cortex due to deficiency of cholinergic system are described in literature, in association with different types of dementia.

Moreover a toxic neuronal lesion is described after stimulation of the platelet aggregation factor, toxic action of the nitric oxide, lipid oxidation and release of free radicals. It is hypothesized that plasmatic cholesterol levels higher, in a given time of exposure, could induce to a risk on peripheral and/or central nervous system. Evidence exists that hypercholesterolemia is a RF for the neuronal aging.

Hypercholesterolemia induces a decreasing in the chromatic vision, the higher visual function, located in the areas 17, 18 and 19 of the cerebral cortex [24]. Dizziness was correlated with hypercholesterolemia as neurotoxic effect by the action on the labyrinth [25].

The findings in elderly Finnish men suggested that high serum cholesterol concentration was an independent RF for Alzheimer's disease. Hypercholesterolemia is one of the main modifiable cardiovascular RFs. Less than $20 \%$ of men with Familial Hypercholesterolemia reach 70 years of age as a result of death from coronary heart disease [26].

The National Cholesterol Education Project sets no upper age limit for lipid screening; however, it recommends "caution in proceeding to drug therapy in the elderly" for primary prevention. Some authors question the utility of cholesterol as a significant risk factor for heart disease mortality in elderly people. Unfortunately, little direct evidence exists about the benefits or burdens of screening and treating octogenarians with high serum lipids.

\section{Diabetes}

The epidemic of type 2 diabetes is clearly linked to increasing rates of overweight and obesity in the U.S. population, but projections by the Centers for Disease Control and Prevention suggest that even if diabetes incidence rates level off, the prevalence of diabetes will double in the next 20 years, in part due to the aging of the population [27].

Other projections suggest that the number of cases of diagnosed diabetes in those aged $\geq 65$ years will increase by 4.5 fold (compared to 3 -fold in the total population) between 2005 and 2050 [28]. The results of the observations revealed a significant association between obesity and diabetes after accounting for genetic factors [29]. Elevations in systemic free fatty acids (FFA) contribute to insulin resistance. Aging per se increases the inflammatory response to excess nutrients and vulnerability to FFA-induced insulin resistance with aging [30].

Data from the Framingham study indicate that diabetic patients are at a higher risk of developing heart failure than non-diabetics. Cardiovascular mortality is double in males and quadruple in diabetic women. Diabetes is also a risk factor for sudden death.

The American Heart Association considers diabetes not as a simple independent RF, but as a "true cardiovascular disease."

\section{Obesity}

Obesity is often associated with co-morbidities such as hypertension, diabetes, atherogenic dyslipidemia, and chronic inflammation, thereby constituting an important risk factor for cardiovascular disease and mortality [31,32]. 
Because of the complexity of obesity, it is likely to be one of the most difficult public health issues our society has faced.

During the past decades, the prevalence of overweight and obesity in the Western world has increased by $30-50 \%$, leading to what has been described as a global epidemic, which involves the associated risks of diabetes, cardiovascular diseases, stroke and death [33].

According to analysis by the National Institute on Aging and scientists from the International Longevity Center, the average American could see his life expectancy reduced by five years due to obesity. Individuals who are obese have a 50 to 100 -percent higher risk of premature death from all causes. This is due to the fact that excess body weight increases your risk of diseases such as cardiovascular disease, type 2 diabetes, stroke and even some types of cancer.

According to US Life Expectancy Statistics obesity decreases the average life span of males and females, 4.9 and 4.1 years, respectively. Frequently, sedentary lifestyle is the "mother" of obesity.

\section{Smoking}

Dr. Raymond Pearl of the University of Johns Hopkins, USA, in 1938, published a paper showing that smokers live less than non-smokers. The negative effects of smoking are well-documented. The association of smoking with an increased risk of acute coronary syndrome and sudden death is clearly established [34]. Tobacco smoking is incompatible with successful aging and compromises life expectancy even in extreme longevity [35].

Dr. Robert Clarke (U.K.) says in a study published by the European Society of Cardiology, is that, "quitting is beneficial at any age and it really is never too late to stop."

\section{Alcohol Intake}

The alcohol intake and survival is controversial. The association between alcohol consumption and survival in very old age seems to have an inverse J-shape; abstention and heavy use is associated with shorter survival compared to light-to-moderate drinking. The US 2010 Guidelines state: An average daily intake of one to two alcoholic beverages is associated with the lowest all-cause mortality and a low risk of diabetes and coronary heart disease among middle-aged and older adults.

In the New Haven EPESE cohort study of 2235 elderly persons (mean age 73.7 years) consumption of about 1.5 to 2 drinks per day was associated with a significantly reduced risk of heart failure: compared with non-drinkers [36].

However, long-term heavy alcohol consumption has been associated with worsening cardiac function, and chronic alcoholism is one of the most important causes of dilated cardiomyopathy [37].

Among 13,894 women in the Nurses' Health Study, investigators prospectively examined alcohol use assessed at midlife in relation to 'successful ageing', which was defined as survival to age 70 years, not having a major chronic disease (such as coronary disease, cancer, stroke, diabetes), and having no major cognitive impairment, physical impairment, or mental health problems [38]. A recent meta-analysis of 143 papers describing the relative drinking of alcohol and cognition found that moderate drinking seems to reduce the risk of dementia and cognitive decline in older subjects [39]. Heavy alcohol use has a significant and negative effect on everyday cognitive performance, and the presence of cognitive and neuropsychological deficits have been observed in heavy drinkers [40].

As well as the 'heart-healthy' benefits of moderate drinking to older people, research is also finding that moderate alcohol consumption may reduce the risk of dementia and Alzheimer's disease.

\section{Uric Acid}

Uric acid, despite being a major antioxidant protecting tissues against the toxic effects of oxygen radicals in the human plasma, both correlates and predicts development of obesity, hypertension, and cardiovascular disease, conditions associated with oxidative stress [41].

A significant association between lower serum uric acid levels in long-lived individuals and their offspring has been observed [42].

\section{Diet}

The American biologist and physiologist Ancel Benjamin Keys (1904-2004) who first established an association between dietary behaviours and risk coronary heart disease, such as the Mediterranean Sea diet [43].

When other factors such as diet were analyzed the authors found a significant association between the consumption of mono and polyunsaturated fats and a lower incidence of cardiovascular diseases, suggesting that the dietary patterns of the Southern European countries, with a low intake of saturated fat and a high intake of fruits and vegetables, was a decisive factor in lower cardiovascular mortality [44].

A daily food intake rich in fruit and vegetables with a low intake of fats and a reduced intake of saturated fatty acids may lower blood pressure in adults [45].

Current prospective cohort data from adults in North America and Europe raise the possibility that a lifestyle pattern that includes a very low meat intake is associated with greater longevity [46]. A diet rich in whole grains, vegetables, fruits, nuts, seeds, legumes, 
and beans extend the life of telomeres that are attached to chromosomes in our cells.

After of this evidence, numerous studies have been made showing the benefits of adherence to a "healthy diet" in reducing cardiovascular disease. Since the pioneering study of Keys et al until the present day, data have been collected from more than 12 crosssectional studies such as: Monica Project [47], Cardia study [48 ], Dash diet [49], OmniHeart [50], among others.

\section{Physical Activity}

The most important variable in lifestyle is physical activity; it is also a very important predictor of mortality and may actually be a superior predictor of mortality than the individual's body mass index.

The World Health Organization has repeatedly confirmed the importance of regular physical activity in old age, in an attempt to preserve functional ability as much as possible. It has recently been reported that even a small amount of regular exercise can have a material impact on longevity.

The American College of Sports Medicine published the Physical Activity Guidelines for Americans, Rockville (MD) U.S. which state that regular physical activity is essential for healthy aging. Adults aged 65 years and older gain substantial health benefits from regular physical activity and these benefits continue to occur throughout their lives [51].

\section{Psychological Attitude}

Favorable attitudes, emotions, personality characteristics, and self-rated health have been associated with successful aging in late life. However, less is known regarding these constructs and their relationships to mental health outcomes in the oldest old persons.

Elderly people who are optimistic have lived 7.6 years on average more than those with a negative mindset [52].

These findings emphasized the important roles of positive attitudes and emotions as well as self-rated health in mental health outcomes in the oldest old. Although, limited by its cross-sectional design, findings suggest these psychological factors may exert protective effects on mental health outcomes in advanced age [53].

\section{Height}

For several decades investigators have been trying to determine whether body habitus is associated with risk for cardiovascular disease.

Several studies observed an increased risk for coronary disease in shorter men [54-58]. Another study has observed an inverse association between height and risk for coronary disease [59]. Data from the NHANES study in a national sample do not support the hypothesis of an inverse height-heart disease relation [60]. The lower men live longer: an American study supports it.

The search recently published in Plos One Medical Magazine, began in 1965 was conducted in between Kuakini Honolulu Heart Program and Kuakini Honolulu-Asia Aging Study, Hawaii, a 60-year long research on a sample of 8,006 Americans men of Japanese origin born between 1900 and 1919; about 1,200 of these men have reached an age of between 90 and 100 years and about 250 are still alive. The researchers this study shows for the first time that people with low stature develop a form of longevity gene protection.

\section{Genetic}

In human leucocytes has been shown that the length of telomeres decreases with age and the shortening is associated with age-related illnesses such as cardiovascular disease.

Vila et al. (Circulation Research-2015) in a polycentric study found a prevalence of a particular variant of the gene encoding BPIEFB4 DNA protein of subjects with extreme longevity.

However, the relationship between elongation of telomeres and longevity is controversial [61-63].

\section{Association of Risk Factors}

The combined effects of cholesterol and high blood pressure on cardiovascular disease mortality have been evaluated in a number of epidemiological studies carried out mainly realized in North American populations $[64,65]$.

Hypertension and dyslipidemia are the most common major cardiovascular disease RFs [66]. Several studies have shown additive effects of cholesterol and high blood pressure on cardiovascular disease mortality.

In a study of French persons aged $<55$ years, the combination of hypertension and hypercholesterolemia dramatically increased the risk for atherosclerosis disease, especially among men. A more aggressive public health policy is needed to prevent the development of RFs in younger subjects [67].

RFs interact positively, such that cardiovascular risk derived from the simultaneous exposure to several RFs is greater than would be expected by the simple addition of the corresponding factors [68]. 


\section{AFRICA Study}

(AFRICA: Acronyms in Spanish of Association of coronary risk factors in old age) [69].

This is a multicenter cross-sectional study developed in Argentina in old age patients was carried out in order to know the prevalence of behavioural, and the presence or absence of RFs and their association. Data were collected on 322 individuals aged 90 years or more, $47 \%$ of whom had a family history of longevity, probably due to some genetic component.

In our series we found a ratio man/woman of 2.8 similar to the general population aged $\geq 90$ years. Actually, in our record of Research Cardiovascular, Foggia, Italy, the ratio women/men reached 1.8 at aged $\geq 80$ years, and increased to 3 at aged $\geq 90$ years.

The majority ate meals comprising mainly fruit, milk and vegetables every day and half of the participants drank a moderate amount of red wine. On average, their body mass index was normal and they regularly took some form of physical activity. The age of the menopause for the long-lived women was 48 years. Frequently, diabetes mellitus (DM) was associated with obesity. No subject had insulin-dependent DM was found.

Interestingly, considering the onset of arterial hypertension started at the high average age of 72 years, it might be due to arteriosclerosis rather than to essential hypertension, a possibility that would be supported by the lack of persons in the study whose hypertension had started before the age of 50 years, time in which there were no angiotensin converting enzyme inhibitors or angiotensin receptors blockers therapy. May be, for the same reason, we detected no association between obesity and hypertension, unlike that seen in children, adolescents and adults. According to these data essential hypertension would label a malignant disease.

Few were found to be current smokers (3.8\%) and even fewer individuals had two or three concurrent RFs:

Interestingly, as the age increases, the height of the population decreases, and the tallest in height are not obese. It could be said that the association of height and obesity could be a RF.

We observed that the height of our patients over 80 years of age was $147 \mathrm{~cm}$ among women and $160 \mathrm{~cm}$ among men, both lower than the average height population.

The relation between height women at 80 years old $(151.1 \mathrm{~cm})$ versus $\geq 87$ years old $(146.1 \mathrm{~cm})$, and men at 80 years old $(160.7 \mathrm{~cm})$ versus men at $\geq 87$ years old $(157.7 \mathrm{~cm})$ was not statistically significant difference, $\mathrm{p}=0.07$ and $\mathrm{p}=0.1$, respectively.

\section{Summary}

Atherosclerosis develops depending on hereditary characteristics and exposure to RFs, environmental factors and lifestyle.

Age and male gender are very strong predictors of cardiovascular events.

The low prevalence of simple RF or its associations in an individual may result in an improved quality of life.

In addition to arterial harm, we could hypothesize that hypercholesterolemia can produce a possible damage of nervous system higher than we know.

Hypertension associated to hypercholesterolemia was as harmful as the smoking habit.

Diet healthy and regular physical activity they are beneficial. Today, there is stronger evidence that increasing adherence to the Mediterranean Diet is associated with lower blood pressure.

The alcohol intake is controversial, varies according to the quantity, the time of consumption and the response of the individual.

Obesity frequently associated to hypertension, during childhood, adolescence, and adult population, is always a major problem by health.

Type II Diabetes mellitus is a strong RF for macro and microvascular disease.

People of short stature could live longer. The tall population could live longer if it is not obese.

Ethnic, geographic, and socio-economic factors should be considered.

Psychological attitude and methodical lifestyle should not to be excluded when evaluating longevity.

We think that wider studies are warranted in order to determine whether control of the RFs at earlier ages could help persons reach an older biological age in a good psychological and physical state.

The control of the several RFs in the population by means of cardiovascular prevention programs is one of the aims of public health and health care systems, and it may contribute to longer life expectancy and a better quality of life. Moreover, the increase in the average life expectancy is a social phenomenon with important health and economic repercussions. 
Executive Summary

We think that wider studies are warranted in order to determine whether control of the RFs at earlier ages could help persons reach an older biological age in a good psychological and physical state.

The control of the several RFs in the population by means of cardiovascular prevention programs is one of the aims of public health and health care systems, and it may contribute to longer life expectancy and a better quality of life. Moreover, the increase in the average life expectancy is a social phenomenon with important health and economic repercussions.

\section{References}

1. The Fifth Report of the Joint National Committee. Detection, Evaluation, and Treatment of High Blood Pressure (JNCV). Arch. Intern. Med. 153: 154-183 (1993).

2. Task Force on Blood Pressure Control in Children. Report of the Second Task Force on Blood Pressure Control in Children-1987. Pediatrics. 79: 1-25 (1987)

3. Pesonen E, Norio R, Hirvonen J, et al. Intimal thickening in the coronary arteries of infants and children as an indicator of risk factors for coronary heart disease. Eur. Heart. J. 11: 53-60 (1990).

4. Newman III WP, Freedman DS, Voors AW, et al. Relation of serum lipoprotein levels and systolic blood pressure to early atherosclerosis: The Bogalusa Heart Study. N. Engl. J. Med. 314: 138-144 (1986).

5. PDAY Research Group. Relationship of atherosclerosis in young men to serum lipoprotein cholesterol concentration and smoking: a preliminary report from the Pathological Determinants of Atherosclerosis in Youth (PDAY) Research Group. JAMA. 264: 3018-3024 (1990).

6. Mahoney LT, Burns TL, Stanford W, et al. Coronary risk factors measured in childhood and young adult life are associated with coronary artery calcification in young adults: The Muscatine Study. J. Am. Coll. Cardiol. 27: 277-284 (1996).

7. Muhonen LE, Burns TL, Nelson RP, Lauer RM. Coronary risk factors in adolescents related to their knowledge of familial coronary heart disease and hypercholesterolemia: The Muscatine Study. Paediatrics. 93: 4 (1994).

8. Marmot MG, Smith GD. Why are the Japanese living longer? BMJ. 299: 1547-1551 (1989).

9. Elliott W. Management of hypertension in the very elderly patient. Hypertension. 44: 800-804 (2004).

10. Krumholz HM, Seeman TE, Merrill SS, et al. Lack of association between cholesterol and coronary heart disease mortality and morbidity ans all-cause mortality in persons older than 70 years. JAMA. 272: 1335-1340 (1994).

11. Thomas F, Guize L, Bean K, Benetos A. Combined effects of pulse pressure and heart rate on cardiovascular mortality. $J$. Hypertens. 19: 863-869 (2001).

12. WHO-MONICA Project. Geographical variation in the major risk factors of coronary heart disease in men and women aged 35-64 years. Wld. Hlth. Stat. Q. 41: 115-140 (1988).

13. Burt VL, Whelton P, Roccella EJ, et al. Prevalence of hypertension in the US adult population. Results from the Third National Health and Nutritional Examination Survey, 1988-1991. Hypertension. 25: 305-313 (1995).

14. McMahon R, Peto R, Cuttler J, et al. Blood pressure, stroke and coronary heart disease. Part 1 . Prolonged differences in blood pressure: prospective observational studies corrected for the regression dilution bias. Lancet. 335: 765-774 (1990).

15. Kannel WB. Blood pressure as a cardiovascular risk factor: prevention and treatment. JAMA. 275: 1571-1576 (1996).

16. Kannel WB, Gordon T. Evaluation of cardiovascular risk in the elderly: The Framingham study. Bull. N. Y. Acad. Med. 54: 573-591 (1978).
17. Dahlöf B, Lindholm LG, Hansson L, Schersten B, Ekbom T, Wester PO. Morbidity and mortality in the Swedish Trial in Old Patients with Hypertension (STOP-Hypertension). Lancet. 338: 1281-1285 (1991).

18. MRC Working Party. Medical Research Council trial of treatment of hypertension in older adults: principal results. $B r$. Med. J. 304: 405-412 (1992).

19. Amery A, Birkenhäger W, Brixko $\mathrm{P}$, et al. Mortality and morbidity results from the European Working Party on High Blood Pressure in the Elderly trial. Lancet. 1: 1349-1354 (1985)

20. Coope J, Warrender TS. Randomized trial of treatment of hypertension in elderly patients in primary care. BMJ. 293: 1145-1151 (1986)

21. Thijs L, Fagard R, Lijnen P, Staessen Y, Van Hoof R, Amery A. A meta-analysis of outcome trials in elderly hypertensives. $J$. Hypertens. 10: 1103-1109 (1992).

22. Kannel WB, Castelli WP, McNamara PM, McKee PA, Feinleib M. Role of blood pressure in the development of congestive heart failure. The Framingham Study. N. Engl. J. Med. 287: 781-787 (1972).

23. Zeglin MA, Pacos J, Bisognano JD. Hypertension in the very elderly: Brief review of management. Cardiol. J. 4: 379-385 (2009)

24. Malavé A, Morell M, Rius F. Chromatic computerized analysis is an early indicator of cardiovascular risk associated with hypercholesterolemia. Rev. Esp. Cardiol. 54: 1417-1425 (2001).

25. Paterno CA. Hypercholesterolemia and possible neurotoxic effect. 1st World Congress of Clinical Lipidology. Budapest, Hungary (2012).

26. Human Genetics Programme. Familial Hypercholesterolemia. Ginebra: $W H O(1998)$

27. Boyle JP, Thompson TJ, Gregg EW, Barker LE, Williamson DF. Projection of the year 2050 burden of diabetes in the US adult population: dynamic modeling of incidence, mortality, and prediabetes prevalence. Popul. Health. Metr. 8: 29 (2010).

28. Narayan KM, Boyle JP, Geiss LS, Saaddine JB, Thompson TJ. Impact of recent increase in incidence on future diabetes burden: US, 2005-2050. Diabetes. Care. 29: 2114-2116 (2006).

29. Pedersen NL, Gustafson Y, Michaëlsson K, Nordström A Risks of myocardial infarction, death, and diabetes in identical twin pairs with different boy mass indexes. JAMA. Intern. Med. 176(10): 1522-1529 (2016).

30. Einstein FH, Huffman DM, Fishman S, et al. Aging per se Increases the Susceptibility to Free Fatty Acid-Induced Insulin Resistance. J. Gerontol. A. Biol. Sci. Med. Sci. 65(8): 800-808 (2010).

31. Melanson KJ, McInnis KJ, Rippe JM, et al. Obesity and cardiovascular disease risk: research update. Cardiol. Rev. 9: 202-207 (2001).

32. Alexander JK. Obesity and coronary heart disease. Am. J. Med. Sci. 321: 215-224 (2001).

33. WHO. Obesity: preventing and managing the global epidemic: report of a WHO consultation. World. Health. Organ. Tech. Rep. Ser. 894: 1-253 (2000). 
34. Burke AP, Farb A, Malcolm GT, Liang YH, Smialek J, Vimani R. Coronary risk factors and plaque morphology in men with coronary disease who died suddendly. N. Engl. J. Med. 336: 1276-1281 (1997)

35. Tafaro L, Cicconetti P, Tedeschi G, et al. Smoking and longevity: an incompatible binomial? Smoking and longevity: an incompatible binomial? Arch. Gerontol. Geriatr. 9: 425-430 (2001).

36. Abramson JL. Moderate alcohol consumption and risk of heart failure among older persons. JAMA. 285: 1971-1977 (2001).

37. Rubin E. Alcoholic cardiomyopathy. Clin. Exp. Res. 18: 111-114 (1994).

38. Sun Q. Alcohol consumption at midlife and successful ageing in women: A prospective cohort analysis in the Nurses' Health Study. PLoS. Med. 8(9): e1001090.

39. Neafsey EJ, Collins MA. Moderate alcohol consumption and cognitive risk. Neuropsy. Disea. Treat. 7: 465-484 (2011).

40. Ling T. Effects of alcohol on subjective ratings of prospective and everyday memory deficits. Alcohol. Clin. Exp. Res. 27: 970-974 (2003).

41. Cutler RG. Urate and ascorbate: their possible roles as antioxidants in determining longevity of mammalian species. Arch. Gerontol. Geriatr. 3(4): 321-348 (1984).

42. Lai JYC, Atzmon G, Melamed ML, et al. Family History of Exceptional Longevity is associated with lower serum uric acid levels in Ashkenazy Jews. J. Am. Geriatr. Soc. 60(4): 745-750 (2012).

43. Keys. Coronary heart disease in Seven Countries. Circulation. 41: 1-211 (1970).

44. Menotti A, Keys A, Kromhout D, et al. Twenty-five-year mortality from coronary heart disease and its prediction in five cohorts of middle-aged men in Finland, The Netherlands, and Italy. Prev. Med. 19: 270-278 (1990).

45. Moore TJ, Conlin PR, Ard J, Laura P. DASH (Dietary Approaches to Stop Hypertension) Diet Is Effective Treatment for Stage 1 Isolated Systolic Hypertension. Hypertension. 38: 155-158 (2001).

46. Singh PN, Sabaté J, Fraser GE. Does low meat consumption increase life expectancy in humans? Am. J. Clin. Nutr. 3: 5265-5325 (2003).

47. Sabaté. Myocardial Infarction and Coronary Deaths in the World Health Organization Monica Project. Circulation. 90: 583-612 (1994).

48. Liu K, Daviglus ML, Loria CM, et al. Healthy lifestyle through young adulthood and the presence of low cardiovascular disease risk profile in middle-age: The Coronary Artery Risk Development in (Young) adults (CARDIA) study. Circulation. 125: 996-1004 (2012).

49. Appel U, Brands MW, Daniels SR, Karanja N, Elmer PJ, Sacks FM. Dietary approaches to prevent and treat hypertension: s scientific statement from the American Heart Hypertension. Hypertension. 47: 296-308 (2006).

50. Appel U, Sacks FM, Carey VJ, et al. OmniHeart Collaborative Research Group. Effects of protein, monounsatured fat, and carbohydrate intake on blood pressure and serum lipids. Results of the Omni Heart randomized trial. JAMA. 294: 2455-2464 (2005).

51. Chodzko-Zajko WJ, Proctor DN, Fiatarone SMA, et al. It was associated with increased risk for myocardial infarction in women but not in men. J. Ame. Coll. Sp. Med. 1: 1510-1530 (2010).

52. Levy B, Slade MD, Kunkel SR, Kasl SV. Longevity increased by positive self-perceptions of aging. J. Personal. Social. Psychol. 2: 261-270 (2002).

53. Kato K, Zweig R, Schechter CB, Barzilai N, Atzmon G. Positive attitude toward life, emotional expression, self-rated health, and depressive symptoms among centenarians and near-centenarians. Aging. Mental. Health. 20(9): 930-939 (2016).
54. Gertler MM, Garn SM, White PD. Young candidates for coronary heart disease. JAMA. 147: 621-625 (1951).

55. Paffenbarger RS, Wolf PA, Notkin J, Thorne MC. Chronic disease in former college students, I: early precursors of fata coronary heart disease. Am. J. Epidemiol. 83: 314-328 (1996).

56. Morris JN, Kagan A, Pattison DC, Gardner M, Raffle PAB. Incidence and prediction of ischaemic heart disease in London busmen. Lancet. 2: 553-559 (1966).

57. Marmot MG, Rose G, Shipley RM, Hamilton PJS. Employment grade and coronary heart disease in British civil servants. J. Epidemiol. Commun. Health. 32: 244-249 (1979).

58. Herbert PR, Rich-Edwards JW, Manson JE, et al. Height and incidence of cardiovascular disease in male physicians. Circulation. 88: 1437-1443 (1993).

59. Kannam J, Levy D, Larson M, Wilson PWF. Short stature was not associated with increased risk for all-cause or cardiovascular mortality in either sex. It was associated with increased risk for myocardial infarction in women but not in men. Circulation. 90: 2241-2247 (1994).

60. Liao Y, McGee DL, Cao G, Cooper RS. Short stature and risk of mortality and cardiovascular diseases: Negative findings from the NHANES I Epidemiologic follow-up study. J. Am. Coll. Cardiol. 27: 678-682 (1996).

61. Atzmon G, Cho M, Cawthon RM, et al. Evolution in Health and Medicine Sackler Colloquium: Genetic variation in human telomerase is associated with telomere length in Ashkenazi centenarians. PNAS. 107(1): 1710-1717 (2010).

62. Gierman HJ, Fortney K, Roach JC, et al. Whole-Genome Sequencing of the World's Oldest People. PLoS. One. 9(11): e112430 (2014).

63. Rajpathak SN, Liu J, Ben-David O, et al. Lifestyle Factors of People with Exceptional longevity. J. Am. Geriatr. Soc. 59(8): 1509-1512 (2011).

64. Neaton JD, Wentworth D. Serum cholesterol. blood pressure, cigarette smoking and death from coronary heart disease. Arch. Int. Med. 152: 56-64 (1992).

65. Lowe LP, Greenlnad P, Ruth KJ, Dyer AR Stamler R, Stamler J. Impact of major cardiovascular disease risk factors, particularly in combination, on 22-years mortality in women and men. Arch. Int. Med. 158: 2007-2014 (1998).

66. Kannel WB. Overall findings and differences by age for 316 099 white men. Am. J. Hypertension. 7: 528-535 (2002).

67. Thomas F, Bean K, Guize L, Quentzel S, Argyriadis P, Benetos A. Combined effects of systolic blood pressure and serum cholesterol on cardiovascular mortality in young $(<55$ years $)$ men and women. Eur. Heart. J. 23: 528-535 (2002).

68. Pérez I, Álvarez F, López P, Jiménez F, Galán A, Banegas JR. Control of cholesterolemia in Spain 2000. An instrument for cardiovascular prevention. Rev. Esp. Cardiol. 53: 815-837 (2000).

69. Paterno CA. Association of Coronary Risk Factors in Old Age (Asociaciòn de Factores de RIesgo Coronario en la Ancianidad). AFRICA study. Rev. Esp. Cardiol. 59(6): 628-631 (2006). 